\title{
A Validated HPTLC Densitometric Method for The Quantitative Determination of Ubidecarenone in Bulk and in Capsule Formulation
}

\author{
Anandakumar Karunakaran', Anjana Elampulakkadu' ', Ramesh Jayaprakash', \\ Senthilkumar Raju' ${ }^{2}$, and Meka Dharshini Lakshmiganesh'
}

\footnotetext{
${ }^{1}$ Department of Pharmaceutical Analysis, Swamy Vivekanandha College of Pharmacy, Elayampalayam, Tiruchengode, Namakkal District, Tamil Nadu, India

${ }^{2}$ Department of Pharmaceutical Chemistry, Swamy Vivekanandha College of Pharmacy, Elayampalayam, Tiruchengode, Namakkal District, Tamil Nadu, India
}

Correspondence: Anandakumar Karunakaran

Email: anandanalysis@gmail.com

Submitted: 23-11-2021, Revised: 15-12-2021, Accepted: 20-12-2021

\begin{abstract}
A new, simple, precise, accurate and rapid high performance thin layer chromatographic method has been developed and validated for the estimation of ubidecarenone in bulk and in capsule formulation. The chromatographic separation was performed on aluminium TLC plates precoated with silica gel $60 F_{254}$ as a stationary phase and methanol:water (7:3) as a mobile phase. Detection was performed densitometrically in the absorbance mode at 280nm for the evaluation of chromatograms. The system has given well sharp peak of ubidecarenone $\left(R_{f}=0.51 \pm 0.02\right)$. The linearity of the method was established in the range of 1-6 $\mathrm{ng} / \mu \mathrm{L}$ with correlation coefficient $\left(r^{2}\right)$ of 0.9995. The method was validated for precision, accuracy, robustness, ruggedness, LOD, and LOQ as per ICH guidelines. The limit of detection was found to be $0.0392 \mathrm{ng} / \mu \mathrm{L}$, whereas the limit of quantitation was found to be $0.1189 \mathrm{ng} / \mu \mathrm{L}$. The percentage label claim for ubidecarenone in the capsule formulation was found to be 99.96 \pm 0.4703 . The accuracy of the method was confirmed by recovery studies. The percentage recovery was found to be in the range of 100.10-101.45\% for ubidecarenone. The \% RSD value was found to be less than 2 . The low $\% R S D$ value indicates that there is no interference due to excipients used in the formulation. Hence, the developed method was found to be simple, precise, accurate, and rapid for the analysis of ubidecarenone in bulk and pharmaceutical formulation and it can be effectively applied for the quality control analysis of ubidecarenone in bulk and pharmaceutical formulation.
\end{abstract}

Keywords: formulation; HPTLC; ICH guidelines; methanol; ubidecarenone 


\section{Introduction}

Ubidecarenone (UBD) (coenzyme Q10, CoQ10, coenzyme Q), is chemically 2,5-cyclohexadiene-1,4dione,2-[(2E,6E,10E,14E,18E,22E,26E,30E,34E)$3,7,11,15,19,23,27,31,35,39$-d ec a meth yl2,6,10,14,18,22,26,30,34,38-tetracontadecaenyl]-5,6-dimethoxy-3-methyl. It is official in USP [1], BP [2] and EP [3]. It is shown in Figure 1. Ubidecarenone is an oil-soluble, vitamin-like substance present in all eukaryotic cells, primarily in the mitochondria are family of compounds that differ in the number of isoprenoid subunits of the sidechains. Ubidecarenone is an important component in the electron transport chain essential for aerobic cellular respiration, generating chemical energy in the form of ATP [4 - 5]. To perform its role as an antioxidant and component in the electron transport chain, ubidecarenone can exist as both reduced and oxidized form. The reduced form of ubidecarenone molecule can easily donate one or both electrons and act as an antioxidant [6]. One of the most important function of ubidecarenone is the inhibition of lipid peroxidation through lipid peroxyl radicals (LOO) inhibition. Ubidecarenone is essential to keep the cardiovascular system in a healthy condition. Heart failure is usually accompanied by the deficiency of CoQ10. The plasma concentration of CoQ10 is considered as a marker of mortality in chronic heart failure and the long-term prognosis of chronic heart failure [7]. It is used for the treatment of migraine [8] and cancer [9-11]. Studies have also revealed that the level of coenzyme Q10is less in diseased gum tissue compared with healthy gum tissue $[12,13]$ improving the gingival health, immune response in gum tissues, and reversing the diseased gum conditions [14-16] improves the periodontitis and gingivitis conditions [17] help in the reduction of radiation damage to the animals' blood [18].

Several HPLC methods were developed for the estimation of CoQ10 in human plasma, raw materials, and dietary supplements [19-24]. Analysis of an inclusion complex of CoQ10 with $\beta$-cyclodextrin was performed by TLC [25]. A sensitive and selective analysis of CoQ10 in human serum was also achieved by negative APCI LC-MS [26]. CoQ10 was analyzed in pharmaceutical formulations using FT-IR spectrophotometric method [27]. CoQ10 stability in pediatric liquid oral dosage formulations and its bioequivalence studies of two marketed formulations of coenzyme Q10 in beagle dogs has been reported [2829]. HPLC method [30-35] and UV spectroscopic method [36-37] also reported for the estimation of ubidecarenone.

To the best of our knowledge, no reports on densitometric HPTLC analytical methods for the analysis of ubidecarenone in bulk and in capsule formulation have been mentioned in the literature. The objective of this study was, therefore,

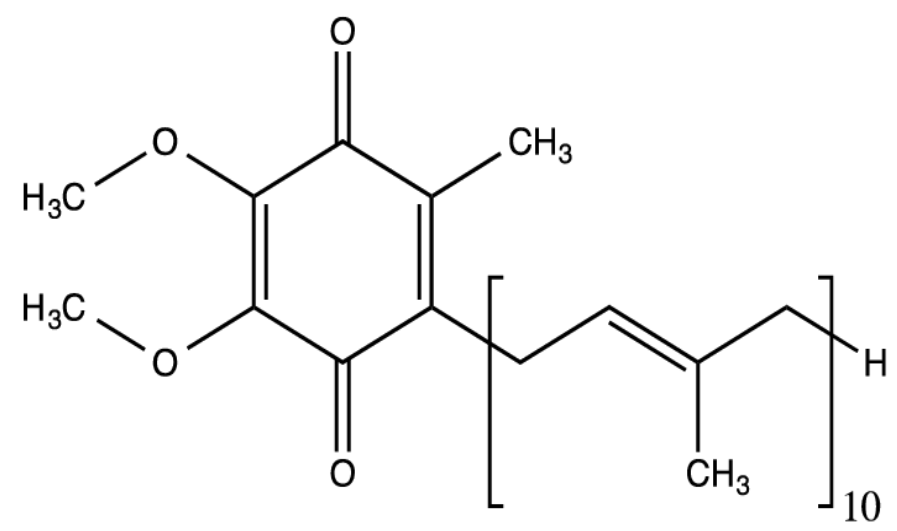

Figure 1. Molecular structure of ubidecarenone 
to develope a simple, accurate, selective, precise, sensitive, robust, and stability-indicating densitometric HPTLC method for the quantitative determination of ubidecarenone in bulk and in capsule formulation.

\section{Materials and methods}

\subsection{Chemicals}

Analytical grade ethanol, acetone, methanol, acetonitrile (Loba Chemie India Limited, Mumbai, India) were used. UBD working standard was supplied by Sai Mirra Innopharm Private Limited, Chennai. The working standard was certified to contain $99.55 \%$ of UBD. Ubi Q300 capsule containing $300 \mathrm{mg}$ of UBD was procured from the local market.

\subsection{Instrumentation and chromatographic con- ditions}

Camag HPTLC apparatus consisting of Linomat V sample applicator (Camag, Muttenz, Switzerland), $100 \mu \mathrm{L}$ syringe (Hamilton-Bonaduz Schweiz, Camag, Switzerland), TLC scanner III (Camag, Muttenz, Switzerland) WinCATS version 1.4.0 software (Camag, Muttenz, Switzerland) were used in the study. Chromatography was performed on Merck silicagel $60 \mathrm{~F}_{254}$ precoated TLC plates (20 cm x $20 \mathrm{~cm}$ with $200 \mu \mathrm{m}$ thickness). Saturation pad (Camag, Muttenz, Switzerland) was used for saturating development chambers. Samples were applied as bands under a stream of nitrogen using the $\mu \mathrm{L}$ syringe. Ascending development to a distance of $7 \mathrm{~cm}$ was performed in a 30 minutes presaturated $20 \times 20 \mathrm{~cm}$ twin trough TLC developing chamber (Camag). Developed plates were dried using hair drier. Densitometric scanning and quantitative evaluation were performed using the TLC scanner and Win CATS version 1.4 .0 software respectively.

\subsection{Selection of mobile phase}

The following solvent mixtures were selected for the method development are acetonitrile:water (5:5), methanol:ethylacetate
(5:5), methanol:acetonitrile (5:5), methanol: water (5:5), methanol:water (7:3). From that, methanol:water (7:3) was selected as a mobile phase. Because, the drug eluted with good peak.

\subsection{Preparation of standard stock solution}

The standard stock solution of UBD was prepared by dissolving $10 \mathrm{mg}$ of UBD in $10 \mathrm{~mL}$ of mobile phase to get a concentration of $1 \mathrm{mg} / \mathrm{mL}$.

\subsection{Selection of wavelength}

One $\mathrm{mL}$ of the standard stock solution was diluted to get the concentration of $10 \mu \mathrm{g} / \mathrm{mL}$. The solution was scanned over the wavelength range of 200-400 nm and the spectrum was obtained. From that spectrum, the $\lambda_{\text {max }}$ was found to be 280 $\mathrm{nm}$ and this was selected as a detection wavelength.

\subsection{Preparation of calibration curve}

$0.1 \mathrm{~mL}$ to $0.6 \mathrm{~mL}$ of standard stock solution was pipetted out in to a series of $100 \mathrm{~mL}$ volumetric flasks. The solutions were diluted with mobile phase to get the concentration range of 1-6 $\mathrm{ng} / \mu \mathrm{L}$ of UBD. The solutions were applied on the TLC plate. The chromatogram was developed and scanned at $280 \mathrm{~nm}$. The peak areas of the respective chromatograms were recorded and the calibration graph was constructed by plotting peak area vs concentration. The regression equation was calculated. The procedure was repeated for six times.

\subsection{Quantification of capsule formulation}

Twenty capsules were weighed accurately and the average weight of each capsule was determined. The mixed content of the capsule powder equivalent to $10 \mathrm{mg}$ of UDB was weighed and transferred into a $100 \mathrm{~mL}$ volumetric flask. The powder was dissolved with mobile phase, made up to $100 \mathrm{~mL}$ with the same and filtered. From this solution, $0.3 \mathrm{~mL}$ was diluted to $100 \mathrm{~mL}$ with mobile phase to get a concentration of $3 \mathrm{ng} / \mu \mathrm{L}$. Six spots were placed on the plate and the chromatograms were recorded. From the peak area, 
the amount of the drug was calculated. The procedure was repeated for six times.

\subsection{Recovery studies}

\subsubsection{Preparation of ubidecarenone raw mate- rial stock solution}

$100 \mathrm{mg}$ of UBD was accurately weighed, dissolved with mobile phase and the volume was made up to $100 \mathrm{~mL}$. The solution contains $1 \mathrm{mg} /$ $\mathrm{mL}$.

\subsubsection{Procedure}

The recovery study was done by adding a known concentration of raw material stock solution of UBD to the pre-analyzed formulation. The capsule powder equivalent to $100 \mathrm{mg}$ of UDB was weighed into three separate $100 \mathrm{~mL}$ volumetric flasks and dissolved with mobile phase. To this 0.2 $\mathrm{mL}, 0.3 \mathrm{~mL}$, and $0.4 \mathrm{~mL}$ of UBD raw material stock solution were added. The solution was made up to $100 \mathrm{~mL}$ and filtered. The clear solution was spotted from each flask and the chromatogram was recorded. The procedure was repeated for three times and the amount of drug recovered was calculated.

\subsubsection{Method validation}

The method was validated in compliance with ICH guidelines [38]. The following parameters were validated.

\subsubsection{Specificity}

Specificity of the method was evaluated to ensure that there was no interference from the excipients present in the formulation. The placebo, sample, and standard solutions were applied on the TLC plates separately and the chromatograms were recorded. The $\mathrm{R}_{\mathrm{f}}$ value of the sample chromatogram was compared with its respective standard.

\subsubsection{Linearity and range}

Linearity of the method was assessed by analyzing the standard stock solution of UBD at six different concentrations. UBD was linear in the concentration range of $1-6 \mathrm{ng} / \mu \mathrm{L}$ at $280 \mathrm{~nm}$. The calibration plot was constructed by plotting peak area against corresponding concentration of drug. The linear regression equation was determined by the method of least squares. The range was determined as $80-120 \%$ of the assay concentration.

\subsubsection{Sensitivity}

Limit of Detection (LOD) and Limit of Quantitation (LOQ) were computed to establish the method sensitivity. For determination of LOD and LOQ, serial standard solutions of UBD $(n=6)$ were applied in six replicates. By observing peak area, calibration curve was constructed. LOD and LOQ were calculated by using LOD $=3.3 \sigma / \mathrm{S}$ and $10 \sigma / \mathrm{S}$, where $\sigma$ is standard deviation of $y$ intercept in regression equation and $S$ is slope of the calibration curve.

\subsubsection{Precision}

The precision of the method was considered at two levels, repeatability and intermediate precision. The repeatability study was confirmed by analysis of formulation was repeated for six times with the same concentration. The intermediates studies were demonstrated by intraday and interday studies. In this, the analysis of formulation was repeated for three times on the same day and on three successive days. The amount of the drug was determined. The precision of the method was expressed as percentage relative standard deviation (\% RSD).

\subsubsection{Accuracy}

To confirm the accuracy of the method, recovery experiments were carried out by the standard addition technique. It was carried out by adding known amount of standard UBD to the preanalysed formulation corresponding in three concentration levels $(80,100$, and $120 \%)$ of the working concentration with excipients and to the working standard solution.

\subsubsection{Robustness}

Robustness of the method was assessed by making small, deliberate changes in the opti- 
mized chromatographic conditions like mobile phase composition, detection wavelength, saturation time of development chamber, time from spotting to development and time from development to scanning were applied. The $\mathrm{R}_{\mathrm{f}}$ value, peak area and \%RSD were calculated.

\subsubsection{Ruggedness}

The ruggedness of the proposed method was performed by the analysis of sample under a variety of test conditions such as different analysts, different instruments and different laboratories. The $\%$ RSD was calculated.

\section{Results and discussion}

\subsection{Method development and optimization}

In this study, different mixtures of various solvents were tried and the composition of mobile phase with a chromatographic result having acceptable and reproducible $\mathrm{R}_{\mathrm{f}}$ value was selected. The detection wavelength was selected based on maximum absorption with optimal sensitivity. The ubidecarenone solution was scanned over the wavelength range 200-400 $\mathrm{nm}$ and the spectrum was recorded. Ubidecarenone shows maximum absorption at $280 \mathrm{~nm}$. Hence, it was selected as a detection wavelength. It is shown in Figure 2.

Initially, two different mixtures of solvents tried were acetonitrile:water (5:5) and methanol:ethyl acetate (5:5). Both compositions resulted in broadened peaks with the $R_{f}$ values of 0.39 and 0.25 , respectively. In methanol:acetonitrile (5:5), the peak was observed for UBD. But the intensity of the peak was decreased due to degradation. Then methanol:water (5:5) was tried. It was good with some unwanted peaks. So, the mobile phase was tried in different proportions i.e. 6:4, 7:3, and $8: 2$. Finally, methanol:water in the ratio of $(7: 3)$ had given the well defined sharp peak without the unwanted peaks. Hence this mobile phase was selected for further analysis. The $\mathrm{R}_{\mathrm{f}}$ value of UBD was found to be $\mathrm{R}_{\mathrm{f}}=0.51$.

After the many trials, the optimized condition that offered best peak (as shown in Figure 3) was on a precoated silica gel plates using methanol:water (7:3) as mobile phase, $10 \mathrm{~mL}$ per single run. Length of chromatogram was $7 \mathrm{~cm}$ with chamber saturation time of 30 minutes. Detection was made at $280 \mathrm{~nm}$.

\subsection{Method validation}

\subsubsection{Specificity}

The specificity is the ability to assess unequivocally the analyte in the presence of components such as impurities, degradation products, obtained experimentally or by inducing their formation [39]. In this study, specificity of the method was checked by comparing the chromatograms obtained for pure UBD, the placebo and the sam-

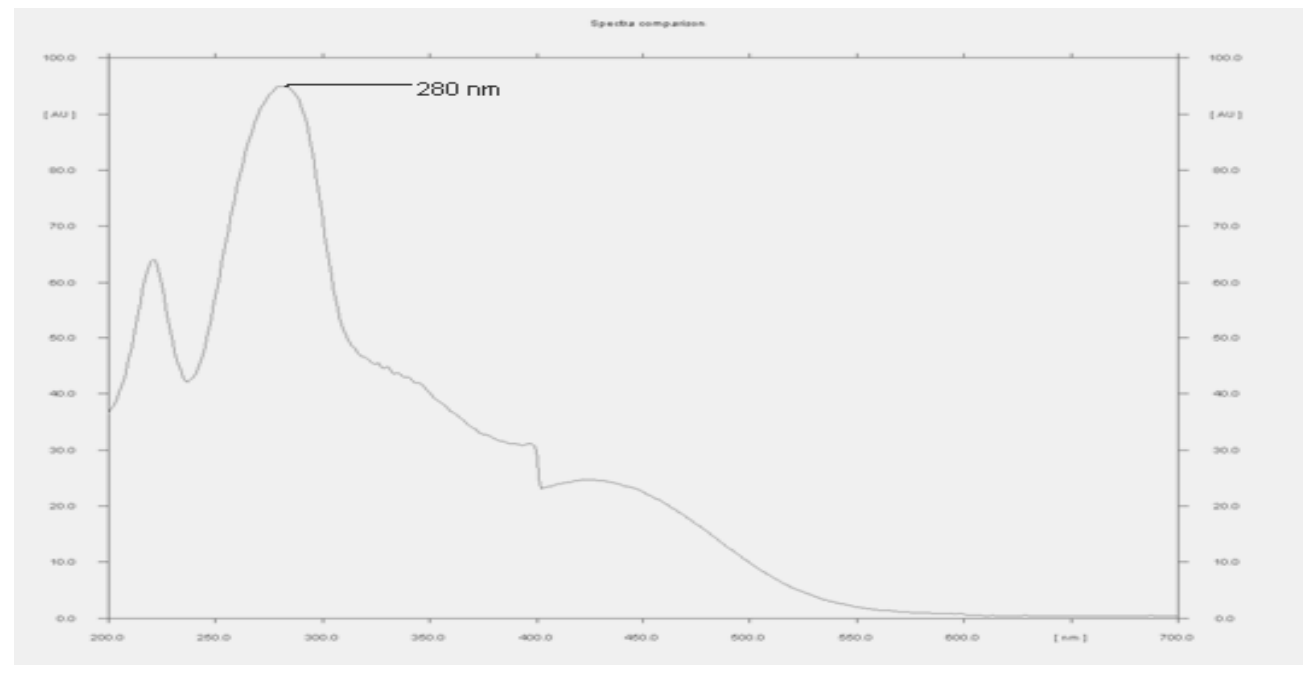

Figure 2. UV spectrum of ubidecarenone in mobile phase by HPTLC 


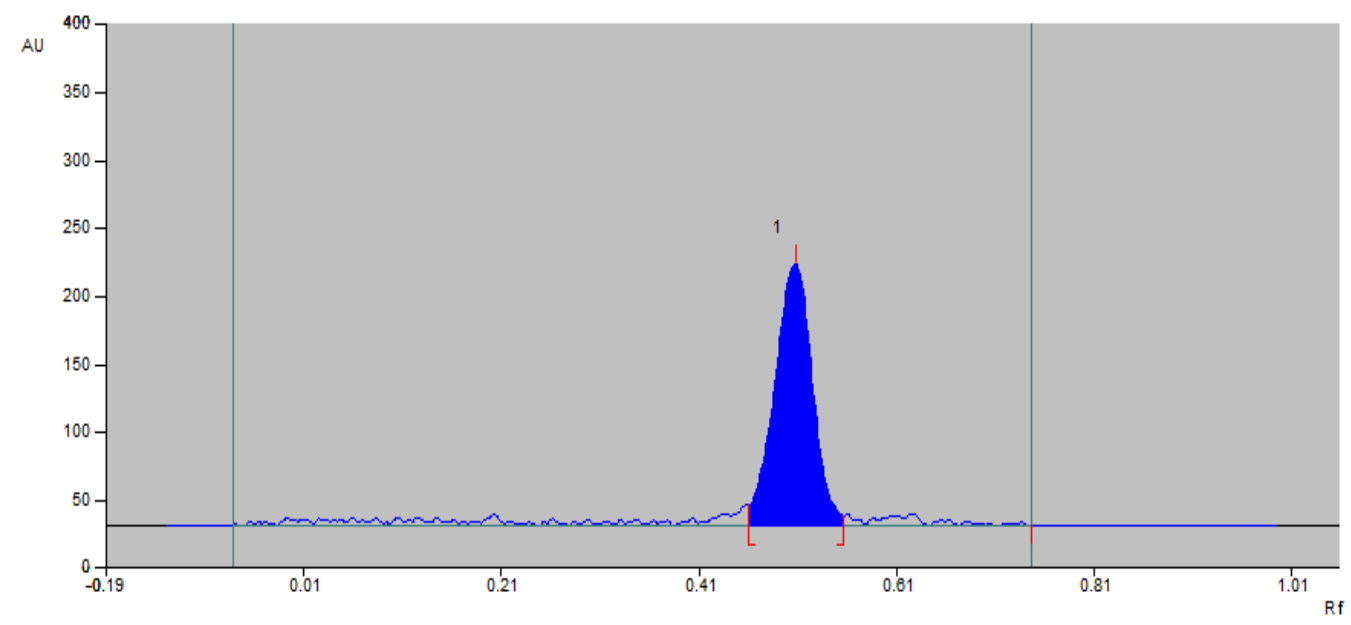

Figure 3. Optimized chromatogram of ubidecarenone

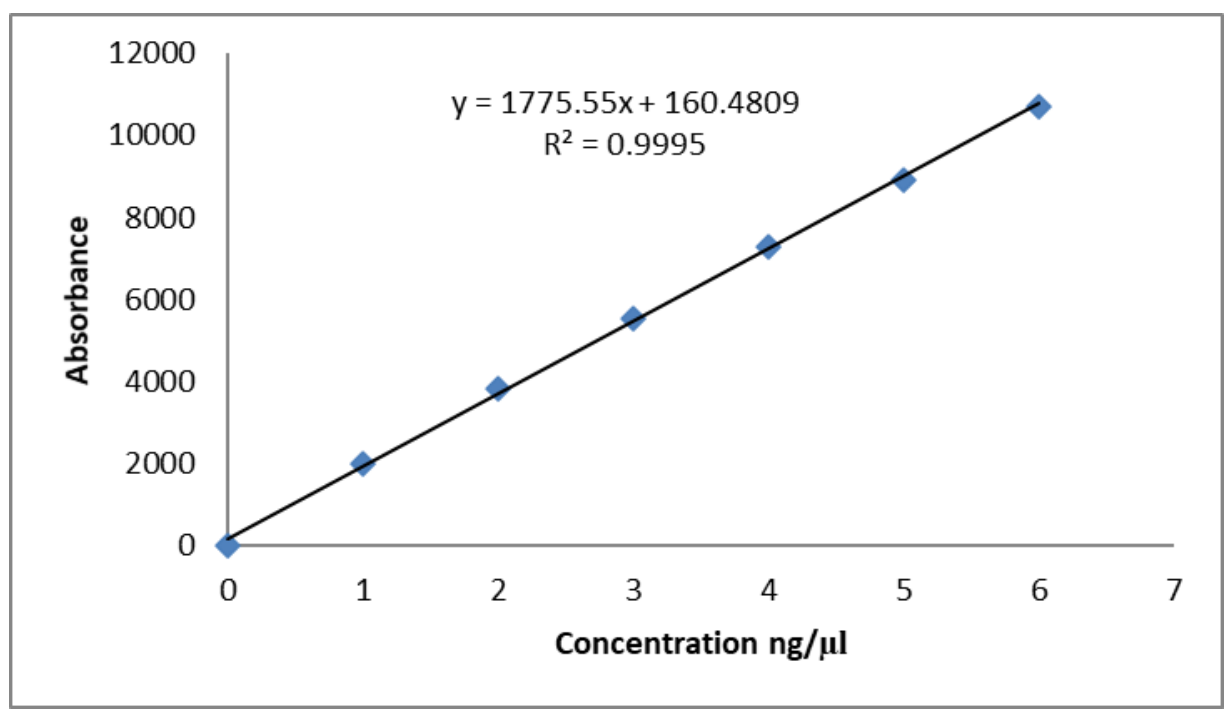

Figure 4. Calibration curve of ubidecarenone

ple. It was proved by comparing the $\mathrm{R}_{\mathrm{f}}$ value of the sample chromatogram with its standard. There is no interference has been observed between the peaks of placebo, sample and standard. Therefore, the developed method was found to be specific.

\subsubsection{Sensitivity}

Sensitivity of the method was confirmed by calculating the limit of detection and limit of quantitation. The LOD and LOQ values for UBD were found to be $0.0392 \mathrm{ng} / \mathrm{mL}$ and $0.1189 \mathrm{ng} /$ $\mathrm{mL}$, respectively. This indicates that the sensitivity of the method was confirmed.

\subsubsection{Linearity}

The developed method was found to be linear in the concentration range of $1-6 \mathrm{ng} / \mu \mathrm{L}$. The correlation coefficient $\left(\mathrm{r}^{2}\right)$ was found to be 0.9995 , which indicates that the linear regression data for the calibration curve shows good linearity with concentration. The calibration curve was shown in Figure 4. The optical characteristics data are shown in Table 1.

\subsubsection{Precision}

Repeatability and intermediate precision of the developed method were expressed in terms of percentage relative standard deviation (\%RSD) 
Table 1. Optical characteristics data

\begin{tabular}{ll}
\hline Parameters & Values* \\
\hline$\lambda_{\max }(\mathrm{nm})$ & 280 \\
Beer's law limit $(\mathrm{ng} / \mu \mathrm{L})$ & $1-6$ \\
Correlation coefficient $(\mathrm{r})$ & 0.9995 \\
Regression equation $(\mathrm{y}=\mathrm{mx}+\mathrm{c})$ & $\mathrm{Y}=1775.55 \mathrm{x}+160.4809$ \\
Slope $(\mathrm{m})$ & 1775.55 \\
Intercept $(\mathrm{c})$ & 160.4809 \\
LOD $(\mu \mathrm{g} / \mathrm{mL})$ & 0.0392 \\
LOQ $(\mu \mathrm{g} / \mathrm{mL})$ & 0.1189 \\
Standard error & 0.1189 \\
${ }^{*}$ Mean of six observations &
\end{tabular}

Table 2. Analysis of formulation by HPTLC method

\begin{tabular}{lllllllll}
\hline $\begin{array}{l}\text { Sample } \\
\text { No. }\end{array}$ & $\begin{array}{l}\text { Labelled } \\
\text { amount } \\
\text { (mg/tablet) }\end{array}$ & $\begin{array}{l}\text { Amount } \\
\text { found } \\
\text { (mg/tablet) }\end{array}$ & $\begin{array}{l}\text { Percentage } \\
\text { obtained* }\end{array}$ & Mean & SD & \% RSD & SE & CI \\
\hline 1 & 300 & 300.63 & 100.21 & 99.96 & 0.4703 & 0.4705 & 0.1920 & 99.18 \\
\hline 2 & & 299.41 & 99.80 & & & & & to \\
\hline 3 & & 302.41 & 100.80 & & & & & 100.73 \\
4 & & 298.86 & 99.62 & & & & & \\
\hline 5 & & 299.38 & 99.79 & & & & & \\
\hline 6 & & 298.65 & 99.55 & & & & & \\
\hline
\end{tabular}

*Mean of six observations of six replicates of $100 \%$ concentration

Table 3. Intraday and interday precision study

\begin{tabular}{|c|c|c|c|c|c|c|c|}
\hline \multirow[t]{2}{*}{ No. } & \multirow[t]{2}{*}{$\begin{array}{l}\text { Concentration } \\
(\mu \mathrm{g} / \mathrm{mL})\end{array}$} & \multicolumn{2}{|c|}{$\begin{array}{l}\text { Percentage } \\
\text { obtained* }\end{array}$} & \multicolumn{2}{|l|}{ SD } & \multicolumn{2}{|l|}{ \% RSD } \\
\hline & & Intra day & Inter day & Intra day & Inter day & Intra day & Inter day \\
\hline 1 & 300 & 99.20 & 99.31 & 0.1896 & 0.1240 & 0.1906 & 0.1248 \\
\hline 2 & 300 & 99.23 & 99.37 & & & & \\
\hline 3 & 300 & 99.19 & 99.34 & & & & \\
\hline Mean & & 99.18 & 99.94 & & & & \\
\hline
\end{tabular}

${ }^{*}$ Mean of six observations of three replicates of $100 \%$ concentration

of the peak area. Repeatability of the method was confirmed by the repeated analysis of formulation for six times. The percentage purity of UBD in formulation was found to be $99.96 \%$. The $\%$ RSD value was calculated and it was found to be
0.4705. The results of the analysis are shown in Table 2. The intermediate precision was done by intraday and interday analysis. The analysis of formulation was repeated three times on the same day and three consecutive days. The \% RSD 
Table 4. Recovery analysis of formulation

\begin{tabular}{llllllll}
\hline No. & $\begin{array}{l}\text { Amount } \\
\text { present } \\
(\boldsymbol{\mu g} / \mathbf{m L})\end{array}$ & $\begin{array}{l}\text { Amount } \\
\text { added } \\
(\boldsymbol{\mu g} / \mathbf{m L})\end{array}$ & $\begin{array}{l}\text { Amount } \\
\text { found } \\
(\boldsymbol{\mu g} / \mathbf{m L})\end{array}$ & $\begin{array}{l}\text { Amount } \\
\text { recovered } \\
(\boldsymbol{\mu g} / \mathbf{m L})\end{array}$ & $\begin{array}{l}\text { \% } \\
\text { Recovered }\end{array}$ & $\begin{array}{l}\text { SD } \\
\text { RSD }\end{array}$ & \\
\hline 1 & 2.9989 & 1.9574 & 4.9762 & 1.9773 & 101.01 & 0.4971 & 0.4928 \\
2 & 2.9989 & 1.9574 & 4.9749 & 1.9760 & 100.95 & & \\
3 & 2.9989 & 1.9574 & 4.9748 & 1.9759 & 100.94 & \\
1 & 2.9989 & 2.9452 & 5.9848 & 2.9859 & 101.38 & & \\
2 & 2.9989 & 2.9452 & 5.9472 & 2.9483 & 100.10 & \\
3 & 2.9989 & 2.9452 & 5.9847 & 2.9858 & 101.37 & & \\
1 & 2.9989 & 3.9552 & 7.0117 & 4.0128 & 101.45 & & \\
2 & 2.9989 & 3.9552 & 6.9647 & 3.9658 & 100.26 & & \\
3 & 2.9989 & 3.9552 & 6.9741 & 3.9752 & 100.50 & 100.88 & \\
\end{tabular}

Table 5. Robustness study by HPTLC method

\begin{tabular}{lllll}
\hline Parameters & $\begin{array}{l}\text { Change in } \\
\text { chromatographic } \\
\text { condition }\end{array}$ & $\mathbf{R}_{\mathbf{f}}$ Value* $^{*}$ & Peak area* & \%RSD \\
\hline Mobile phase composition & $6: 4$ & 0.50 & 5726 & 1.2622 \\
& $7: 3$ & 0.51 & 5667 & 0.8792 \\
Detection wavelength (nm) & $8: 4$ & 0.50 & 5692 & 1.2728 \\
& 275 & 0.50 & 5376 & 0.9233 \\
& 280 & 0.51 & 5667 & 0.8792 \\
\hline
\end{tabular}

*Mean of six observations of six replicates

Table 6. Robustness study by HPTLC method

\begin{tabular}{llllll}
\hline No & Category & $\begin{array}{l}\text { Labelled amount } \\
\text { (mg/tablet) }\end{array}$ & Mean* & SD & \%RSD \\
\hline 1 & ANALYST I & 300 & 99.60 & 0.2305 & 0.2314 \\
2 & ANALYST II & 300 & 99.40 & 0.1176 & 0.1183 \\
\hline
\end{tabular}

*Mean of six observations

value for the intraday and interday analysis of UBD was found to be 0.1906 and 0.1248 respectively. This is shown in Table 3. The \% RSD values for repeatability and intermediate precision were found to be less than $2 \%$. This indicated that the method was found to be precise.

\subsubsection{Accuracy}

Accuracy of the method was confirmed by recovery studies. The percentage recovery was found to be in the range of $100.10 \%$ to $101.45 \%$.
The \% RSD was found to be 0.4928 . The low \% RSD indicates that there is no significant interference due to excipients used in formulation. This ensures that the method is more accurate. The results of the recovery studies are shown in Table 4.

\subsubsection{Robustness}

Robustness of the method was performed by making small deliberate changes in described chromatographic conditions. No significant differences were observed in the $\mathrm{R}_{\mathrm{f}}$ value and peak 
area. The $\%$ RSD was found to be 0.8792 . The low $\%$ RSD indicates that the method is robust. The results are shown in Table 5.

\subsubsection{Ruggedness}

Ruggedness of the method was performed by the analysis of formulation with the help of two different analysts. The \% RSD was found to be 0.2314 and 0.1183 , respectively. The results are shown in Table 6.

\subsubsection{Analysis of capsule formulation}

The amount of the drug was found to be 99.96 \pm 0.4703 . The $\%$ RSD was found to be 0.4705 . The low \% RSD indicates the suitability of the method for the analysis of UBD in the pharmaceutical dosage form.

\subsubsection{Comparision of the developed method with reported methods}

When comparing the proposed method with the reported methods, there are HPLC and UV spectroscopic methods were reported. The concentration range used for the linearity was very high for both HPLC $(60-180 \mu \mathrm{g} / \mathrm{mL})$ and UV spectroscopic method $(10-80 \mu \mathrm{g} / \mathrm{mL})$, but in the proposed method was 1-6 ng/ $\mu \mathrm{L}$. The LOD and LOQ were very low for the proposed method and hence the developed method was considered as sensitive. Even though UV spectroscopic method is simple, the method lack in sensitivity. Hence the developed method was found to be sensitive and accurate when compared to the reported methods.

\section{Conclusion}

A new high performance thin layer chromatographic method (HPTLC) has been developed and validated for determination of UBD in bulk and in capsule formulation. Reliable HPLC analysis of this drug can be performed on TLC plate coated with silica gel $60 \mathrm{~F}_{254}$. The mobile phase was methanol:water (7:3). Densitometry analysis was performed at $280 \mathrm{~nm}$. The method is simple, sensitive (LOD and LOQ were 0.0392 and $0.1189 \mathrm{ng} /$ $\mathrm{mL}$, respectively), precise (RSD $\pm 2 \%$ ) and linear over the range 1-6 $\mathrm{ng} / \mu \mathrm{L}$ with $\mathrm{r}^{2}$ value of 0.9995 . The developed HPTLC method was found suitable for determination of UBD in capsule formulation without any interference from the excipients. Therefore, the developed HPTLC method offers many advantages in terms of cost, reduced analysis run time, simplicity, precision, accuracy, robustness etc. Thus, the proposed HPTLC method was effectively utilized for the routine quality control analysis of ubidecarenone in bulk and in capsule formulation.

\section{Acknowledgement}

The authors are very much thankful to Dr. G. Murugananthan, Principal, Swamy Vivekanandha College of Pharmacy, Tiruchengode, for his support and also thankful to the management for providing the necessary facilities to carry out the research work successfully.

\section{References}

1. The United States Pharmacopoeia/The National Formulary, The Official Compendia of Standards. Vol I. The United State Pharmacopoeial Convention, Rockville, MD. 2008: 3137.

2. British Pharmacopoeia. Vol II. British Pharmacopoeia Commission Office, London. 2011: 2226-27.

3. European Pharmacopoeia. Vol II. European Pharmacopoeia Commission. 2005: 2657-8.

4. Ernster L, Dallner G. Biochemical, physiological and medical aspects of ubiquinone function. Biochimica et biophysica acta. 1995;1271(1):195204.

5. Leonard MA, Sharp RE, Darrouzet E, Moser CC, Ohnishi T, Gibney BR, Daldal F, Dutton PL. Coenzyme Q oxidation - reduction reactions in mitochondrial electron transport. In Kagan, VE; Quinn, PJ. Coenzyme Q: Molecular mechanisms in health and 
disease. Boca Raton: CRC Press, 65 - 82.

6. Michael B, Schachter MD. http://www.mbschachter.com/coenzyme_q10.htm.

7. Molyneux SL, Florkowski CM, George PM. Coenzyme Q10: An independent predictor of mortality in chronic heart failure. Journal of the American College of Cardiology. 2008;52(18):1435-41.

8. Sandor PS, Clementi D, Coppola L, Saenger G, Fumal U, Magis A, Feidel D, Agosti L. Efficacy of coenzyme Q 10 in Migraine prophylaxis: A randomized controlled trial. Neurology. 2005;64(4):713-5.

9. Sakano K, Takahashi M, Kitano M, Sugimura T, Wakabayashi K. Suppression of Azoxymethane induced colonic premalignant lesion formation by coenzyme Q 10 in rats. Asian Pacific Journal of Cancer Prevention. 2006; 7(4):599-603.

10. Clinical Trials. gov NCT 00096356 . Coenzyme Q 10 in relieving treatment - related fatigue in women with breast cancer, 2008.

11. Clinical Trials. gov NCT 00976131. Study of CoQ 10 during one cycle of doxorubicin treatment for breast cancer, 2013.

12. Littarru GT, Nakamura R, Ho L, Folkers K, Kuzell WC. Deficiency of coenzyme Q 10 in gingival tissue from patients with periodontal disease. Proceedings of the National Academy of Sciences. 1971;68(10):2332-5.

13. Nakamura R, Littaru GT, Folkers K, Wilkinson EG. Study of Coq10 - Enzyme in gingival from patients with perodontial disease and evidence for a deficiency of coenzyme Q 10. Proceedings of the National Academy of Sciences. 1974;71(4):1456-60.

14. Mc Ree JT, Hanioka T, Shizukuishi S, Folkers K. Therapy with coenzyme Q 10 for patients with periodontal diseases. Journal of Dental Health. 1993;43(5):659-66.

15. Folkers K, Hanioka T, Xia L, Mc Reejr J, Langsjoen P. Coenzyme Q 10 increases T4/T8 ratios of lymphocytes in ordinary subjects and relevance to patients having the aids related complex. Biochemical and Biophysical Research Communications. 1991;176(2):786-91.

16. Wilkinson EG, Arnold RM, Folkers K. Bioenergetics in clinical medicine. VI. Adjunctive treatment of periodontal diseases with coenzyme Q 10. Re- search Communications in Chemical Pathology and Pharmacology. 1976;14(4):715-9.

17. Hanioka T, Tanaka M, Ojima M, Shizukuishi S, Folkers K. Effect of topical application of coenzyme Q 10 on adult periodontitas. Molecular Aspects of Medicine. 1994;15(s 1):241-8.

18. Koryagin AS, Krylova EV, Luk'yanova LD. Effect of ubiquinone - 10 on the blood system in rats exposed to radiation. Experimental Biology and $\mathrm{Me}-$ dicine. 2202;133(6):562-64.

19. Tang PH, Miles MV, De Grauw A, Hershey A, Pesce A. HPLC analysis of reduced and oxidised coenzyme Q10 in human plasma. Clinical Chemist. 2001;47(7):256-65.

20. Lunetta S, Roman M. Determination of coenzyme Q 10 content in raw materials and dietary supplements high performance liquid chromatography - UV: collaborative study. Journal of Association of Analytical Chemist International. 2008;91(40):702-8.

21. Graves S, Sikorska M, Borowy - Boroski H, Ho RJH, Bui T, Woodhouse C. Analysis of coenzyme Q 10 content in human plasma and other biological samples. Methods in Molecular Biology. 1998;108(2):353-65.

22. Surasi VS, Sakamoto N, Ashida N, Kishi T, Folkers K. Quantitative determination of coenzyme Q 10 in human blood for clinical studies. Analytical Biochemistry. 1984;142(1):155-8.

23. Karpinska J, Mikoluc B, Motkowski R, PiotrowskaJastrzebska J. HPLC method for simultaneous determination of retinol, alpha-tocopherol and coenzyme Q10 in human plasma. Journal of Pharmaceutical and Biomedical Analysis. 2006;42(2):232-6.

24. Li K, Shi Y, Chen S, Li W, Shang X, Huang Y. Determination of coenzyme Q10 in human seminal plasma by high-performance liquid chromatography and its clinical application. Biomedical Chromatography. 2006;20(10):1082-6.

25. Prosek M, Smidovnik A, Fir M, Strazisar M. Electrochemical analysis of coenzyme Q 10 and reduced coenzyme Q 10. 2006; United States Patent. 6984308.

26. Hansen G, Christensen P, Tuchsen E, Lund T. Sensitive and selective analysis of coenzyme Q 10 in 
human serum by negative APCi - LC - MS. Analyst. 2004;129 1):45-50.

27. Bunaciu AA, Aboul - Enein HY, Fleschin S. FT - IR spectrophotometric analysis of coenzyme Q 10 (coQ 10) and its pharmaceutical formulations. Preparative Biochemistry and Biotechnology. 2007;37(1):59-65.

28. Estavez PN, Tripodi V, Buontempoy F, Lucangioli S. Coenzyme Q 10 stability in pediatric liquid oral dosage formulations. Farmacia hospitalaria. 2012;36(6):492-7.

29. Kommuru TR, Ashraf M, Khan MA, Reddy IK. Stability and bioequivalence study of two marketed formulations of coenzyme Q 10 in Beagle dogs. Chemical and Pharmaceutical Bulletin. 1999;47(7):1024-8.

30. Caroline grace A, Prabha T, Jagadeeswaran M, Srinivasan K, Sivakumar T. Analytical method development for simultaneous determination of ubidecarenone and vitamin $\mathrm{E}$ acetate in capsule dosage form by HPLC. International Journal of Pharmacy and Pharmaceutical Sciences. 2019;11(1):79-84.

31. Saravanan VS, Revathi R, Meera Nadhini V. Method development and validation for the simultaneous estimation of lycopene and ubidecarenone by RP- HPLC in combined pharmaceutical dosage form. Journal of Drug Delivery and Therapeutics. 2016;6(5):46-51.

32. Abdul Muheem, Faiyaz Shakeel, Sobiya Zafar, Mohammed Asadullah Jahangir, Musarrat Husain Warsi, Gaurav Kumar Jain, Farhan Jalees Ahmad. Development and validation of stability-indicating liquid chromatographic (RP-HPLC) method for estimation of ubidecarenone in bulk drug and formulations using quality by design (QBD) approach. Brazilian Journal of Pharmaceutical Sciences. 2017;53(4): 5-11.
33. Prajapati M K, Kannappan N, Sasidharan DK, Ramkumar P, Panda PP. Analytical Method Development and Validation of Atorvastatin Calcium and Ubidecarenone Tablet by RP-HPLC. International Journal of Pharmaceutical Sciences and Research. 2011;2(7):1679-82.

34. Gleize B, Steib M, André M, Reboul E. Simple and fast HPLC method for simultaneous determination of retinol, tocopherol, coenzyme Q (10) and carotenoids in complex samples. Food Chemistry. 2012;134(4):2560-4.

35. Mahendra K, Murthy YLN, Narasimha Rao CV, Bala Murali Krishna K. Determination of Ubiquinone Q10 (Coenzyme Q10) and Its Synthesis Related Impurities by High -Performance Liquid Chromatography (HPLC) and Mass Spectrometry (MS). International Journal of Pharmtech Research. 2011;3(3):1467-77.

36. Anandakumar K, Sangeetha VP, Sindhuja V, Sri Iswarya S, Ramesh J, Arun NT, Raja M. Validated UV spectrophotometric Method for the Quantitative Determination of Ubidecarenone. Research Journal of Pharmacy and Technology. 2020;13(5):2233-7.

37. Mailvelan R, Mounnissamy VM, Selvamani P, Rajesh J, Raviraj T. Development and validation of UV spectrophotometric methods for the simultaneous estimation of ubidecarenone (coenzyme q-10) and clomifene citrate in bulk and tablet dosage forms. Asian Journal of Research in Chemistry and Pharmaceutical Sciences. 2013;1(1):23-30.

38. ICH Harmonized Tripartite Guideline: Text on Validation of Analytical Procedures, Text and Methodology, Q2(R1), International Conference on Harmonization, Geneva 2005; 1-17.

39. Ermer J. Validation in Pharmaceutical Analysis, Part I: an integrated approach. Journal of Pharmaceutical and Biomedical Analysis. 2001;24:755-67. 